\title{
Aggregation induced emission and amplified explosive detection of tetraphenylethylene- substituted polycarbazoles
}

\begin{abstract}
Wenyue Dong, ${ }^{a}$ Teng Fei, ${ }^{\mathrm{b}}$ Alex Palma-Cando ${ }^{\mathrm{a}}$ and Ullrich Scherf ${ }^{\star a}$
Novel conjugated polymers based on 3,6-carbazole repeat units were synthesized by nickel-catalyzed Yamamoto coupling under microwave heating. The resulting poly(3,6-carbazole)s contain tetraphenylethylene (TPE) units in their side chains. The resultant polymers show aggregation induced emission (AIE) behavior. Hereby, the photoluminescence (PL) intensity of PCzTPE0.5 in 90\% water-THF is 35 times higher than that in pure THF, connected to the introduction of TPE side chains. The ability of polymer PCzTPEO.5 for explosive sensing was also studied. A maximum Stern-Volmer quenching constant of $1.26 \times 10^{6} \mathrm{M}^{-1}$ was observed for PL quenching of PCzTPE0.5 aggregates by trinitrobenzene (TNB). A solid state paper strip test based on PCzTPE0.5 and PCzTPE also demonstrates effective PL quenching towards both TNB vapor and solution.
\end{abstract}

Received 19th February 2014 Accepted 11th March 2014

DOI: 10.1039/c4py00251b

www.rsc.org/polymers developed for explosive detection, such as gas chromatography, ${ }^{24}$ mass spectrometry, ${ }^{25,26}$ surface enhanced Raman spectroscopy, ${ }^{27}$ ion mobility spectrometry, ${ }^{28,29}$ electrochemical sensing, ${ }^{30}$ PL spectroscopy, ${ }^{31-34}$ and others. Among them, PL sensors based on conjugated polymers ${ }^{35}$ have been widely tested because of their simplicity and high sensitivity. Trinitroaromatic compounds containing three electron-withdrawing nitro groups are potent electron acceptors. The working principle of PL sensors for nitroaromatic compounds is based on a photo-induced electron transfer from donor (conjugated polymer) to acceptor (nitroaromatic compound) thus resulting in PL quenching. Recently, AIE luminogens have been used in PL sensors for the detection of nitroaromatics $^{36-42}$ due to their high solid state fluorescence quantum yields. Moreover, their twisted structure creates an increased number of 3D exciton diffusion channels, thus enhancing the quenching efficiency.

In this study, we prepared novel AIE-active conjugated polymers and investigated their ability for sensing nitroaromatic compounds. Two carbazole-based polymers (PCzTPE and PCzTPE0.5) with TPE side chain units were successfully synthesized. The 3,6-carbazole repeat units ${ }^{43-45}$ were chosen for constructing the polycarbazole backbone since their electron-donor character should be beneficial for the interaction with electron-poor trinitroaromatics. The incorporation of TPE into the side chains guarantees AIE activity, without strongly affecting the electronic properties of the polycarbazole backbone. Based on this design principle we expected a high sensitivity for the detection of nitroaromatic compounds. Our novel polymers are the first polymeric AIE materials with the AIE active groups in the side chain. 


\section{Experimental}

\section{Characterization of materials}

NMR spectra were recorded on a Bruker AVANCE 400 or AVANCE III 600. ${ }^{1} \mathrm{H}$ and ${ }^{13} \mathrm{C}$ NMR spectra were recorded with tetramethylsilane (TMS) as an internal standard. Gel permeation chromatography (GPC) measurements were carried out on a PSS/ Agilent SECurity GPC System equipped with polystyrene gel columns using chloroform as an eluent. APLI (Atmospheric Pressure Laser Ionization) measurements were carried out on a Bruker Daltronik Bremen with micrOTOF. UV-visible absorption spectra were recorded on a Jasco V-670 spectrometer and PL spectra on a Varian CARY Eclipse F2500. Elemental analyses were performed on a Vario EL II (CHNS) instrument. Thermal gravimetric analysis (TGA) was undertaken on a TGA/DSC1 STAR System (Mettler Toledo) at a heating rate of $10{ }^{\circ} \mathrm{C} \mathrm{min}^{-1}$ and an

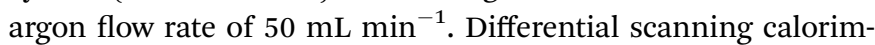
etry (DSC) was performed on a DSC1 STAR System (Mettler Toledo) at a heating rate of $10{ }^{\circ} \mathrm{C} \mathrm{min}^{-1}$ under argon. The PL quantum efficiencies of polymer films were measured with an integrating sphere. Cyclic voltammetry (CV) measurements of the polymer films were performed on a standard three-electrode electrochemical cell attached to a VersaSTAT 4 electrochemical workstation in dichloromethane for polymers and acetonitrile for trinitrobenzene (TNB) with $0.1 \mathrm{M}$ tetrabutylammonium perchlorate as a supporting electrolyte at a scan rate of $0.1 \mathrm{~V} \mathrm{~s}^{-1}$ for polymers and $0.2 \mathrm{~V} \mathrm{~s}^{-1}$ for TNB. The potentials were measured against an $\mathrm{Ag} / \mathrm{Ag} \mathrm{NO}_{3}$ reference electrode $\left(0.1 \mathrm{M} \mathrm{AgNO}_{3}\right.$ in acetonitrile/0.6 V vs. NHE). The onset potentials were determined from the intersection of two tangents drawn at the rising current and background current of the cyclic voltammogram.

\section{Synthesis}

All reagents were obtained from commercial suppliers and were used without further purification. All reactions were carried out under an argon atmosphere using standard and Schlenk techniques. The solvents used were of commercial p.a. quality.

1-(4-Fluorophenyl)-1,2,2-triphenylethylene (1). To a solution of diphenylmethane $(8.08 \mathrm{~g}, 48 \mathrm{mmol})$ in dry tetrahydrofuran (80 mL) $2.8 \mathrm{M}$ solution of $n$-butyllithium in hexane (48 mmol) was added at $0{ }^{\circ} \mathrm{C}$ under an argon atmosphere. The resulting orange-red solution was stirred for $1 \mathrm{~h}$ at that temperature. To this solution 4-fluorobenzophenone (8.00 g, $40 \mathrm{mmol})$ was added, and the reaction mixture was allowed to warm up to room temperature overnight. The reaction was quenched with the addition of an aqueous solution of ammonium chloride. The organic layer was extracted with chloroform, and the combined organic layers were washed with a saturated brine solution and dried over anhydrous $\mathrm{MgSO}_{4}$. The solvent was evaporated, and the resulting crude alcohol (containing excess diphenylmethane) was subjected to acid-catalyzed dehydration as follows.

The crude alcohol was dissolved in about $250 \mathrm{~mL}$ of toluene containing $p$-toluenesulphonic acid $(2.0 \mathrm{~g}, 10.5 \mathrm{mmol})$ in a $500 \mathrm{~mL}$ flask, and the mixture was refluxed overnight. The toluene layer was washed with $10 \%$ aqueous $\mathrm{NaHCO}_{3}$ solution and dried over $\mathrm{MgSO}_{4}$ and evaporated to afford the crude tetraphenylethylene derivative. The crude product was purified by recrystallization from the mixture of dichloromethane and methanol to give the target compound as a white solid in $71 \%$ yield $(10.0 \mathrm{~g}) .{ }^{1} \mathrm{H}$ NMR (400 MHz, $\left.\mathrm{C}_{2} \mathrm{D}_{2} \mathrm{Cl}_{4}\right) \delta$ 7.15-7.07 (m, 9H), 7.06-6.95 (m, 8H), 6.80 $(\mathrm{t}, J=8.8 \mathrm{~Hz}, 2 \mathrm{H}) .{ }^{13} \mathrm{C} \mathrm{NMR}\left(\mathrm{C}_{2} \mathrm{D}_{2} \mathrm{Cl}_{4}, 100 \mathrm{MHz}\right) \delta(\mathrm{ppm}) 160.24$, 143.73 , 143.69, 143.62, 141.41, 140.01, 139.97, 139.94, 133.23, $133.15,131.51,128.06,128.00,127.95,126.76,126.69,114.94$, 114.73.

1-[4-(3,6-Dibromocarbazole-9-yl)phenyl]-1,2,2-triphenylethylene (2). A solution of compound 1 (3.00 g, $8.56 \mathrm{mmol}$ ), 3,6dibromocarbazole $(3.06 \mathrm{~g}, 9.42 \mathrm{mmol})$ and $\mathrm{K}_{3} \mathrm{PO}_{4}(9.08 \mathrm{~g}, 42.8$ $\mathrm{mmol})$ in DMF $(120 \mathrm{~mL})$ was stirred at $150{ }^{\circ} \mathrm{C}$ for $24 \mathrm{~h}$ under an argon atmosphere. The reaction mixture was quenched with water and extracted with chloroform. The organic phases were collected, dried over $\mathrm{MgSO}_{4}$, and concentrated in a vacuum. The product was purified by silica gel chromatography (eluent: hexane-dichloromethane $=4 / 1$ ) to give the desired compound as a white solid in $25 \%$ yield $(1.4 \mathrm{~g}) .{ }^{1} \mathrm{H}$ NMR (400 $\left.\mathrm{MHz}, \mathrm{C}_{2} \mathrm{D}_{2} \mathrm{Cl}_{4}\right)$ $\delta 8.19(\mathrm{~d}, J=1.9 \mathrm{~Hz}, 2 \mathrm{H}), 7.53(\mathrm{dd}, J=8.7,1.9 \mathrm{~Hz}, 2 \mathrm{H}), 7.26(\mathrm{~d}$, $J=8.6 \mathrm{~Hz}, 2 \mathrm{H}), 7.24-7.12(\mathrm{~m}, 15 \mathrm{H}), 7.12-7.06(\mathrm{~m}, 4 \mathrm{H}) .{ }^{13} \mathrm{C} \mathrm{NMR}$ $\left(\mathrm{C}_{2} \mathrm{D}_{2} \mathrm{Cl}_{4}, 100 \mathrm{MHz}\right) \delta 143.94,143.66,143.42,143.20,142.42$, 140.13 , 139.99, 134.69, 133.20, 131.66, 131.60, 131.52, 129.69, 128.19, 128.05, 128.03, 127.04, 126.99, 126.10, 124.06, 123.44, 113.26, 111.94. MS (APLI): $m / z$ calcd 655.03; found 655.03. Elemental anal. calcd for 2: C, 69.64\%; H, 3.84\%; N, 2.14\%. Found: C, 69.17\%; H, 3.84\%; N, 2.16\%.

3,6-Dibromo-9-octylcarbazole (3). 3,6-Dibromocarbazole (5.0 g, $1.55 \mathrm{mmol}$ ) and tetrabutylammonium bromide (TBABr) (500 mg, $1.55 \mathrm{mmol}$ ) were dissolved in $100 \mathrm{~mL}$ of DMSO under argon. Aqueous $\mathrm{NaOH}$ solution $\left(1 \mathrm{~g} \mathrm{~mL}^{-1}, 8 \mathrm{~mL}\right)$ was added to the mixture, and the mixture was stirred at $60{ }^{\circ} \mathrm{C}$ for $5 \mathrm{~min}$. Then, 1-bromooctane ( $4 \mathrm{~mL}, 0.023 \mathrm{~mol}$ ) and $10 \mathrm{~mL}$ of DMSO were added and the reaction mixture was heated to $90{ }^{\circ} \mathrm{C}$ overnight. The reaction mixture was quenched with water and extracted with chloroform. The organic phases were collected, dried over $\mathrm{MgSO}_{4}$ and concentrated under vacuum. The product was purified by silica gel chromatography (eluent: hexanedichloromethane $=3 / 1$ ) to give the desired compound as a white solid in $81 \%$ yield (5.4 g). ${ }^{1} \mathrm{H} \mathrm{NMR}\left(400 \mathrm{MHz}, \mathrm{C}_{2} \mathrm{D}_{2} \mathrm{Cl}_{4}\right) \delta$ 8.15 (s, 2H), 7.58 (dd, $J=8.7,1.9 \mathrm{~Hz}, 2 \mathrm{H}), 7.30$ (d, $J=8.7 \mathrm{~Hz}$, $2 \mathrm{H}), 4.23(\mathrm{t}, J=7.0 \mathrm{~Hz}, 2 \mathrm{H}), 1.88-1.74(\mathrm{~m}, 2 \mathrm{H}), 1.38-1.15$ $(\mathrm{m}, 10 \mathrm{H}), 0.87(\mathrm{t}, J=6.8 \mathrm{~Hz}, 3 \mathrm{H}) .{ }^{13} \mathrm{C} \mathrm{NMR}\left(\mathrm{C}_{2} \mathrm{D}_{2} \mathrm{Cl}_{4}, 100 \mathrm{MHz}\right) \delta$ (ppm) 139.57, 129.37, 123.58, 123.49, 112.16, 110.88, 43.69, $32.03,29.58,29.40,29.15,27.49,22.91,14.48$. MS (APLI): $\mathrm{m} / \mathrm{z}$ calcd 437.02; found 437.06. Elemental anal. calcd for 3: C, $54.94 \%$; H, 5.30\%; N, 3.20\%. Found: C, 54.91\%; H, 5.58\%; N, $3.20 \%$.

Polymer PCzTPE. A solution of compound 2 (400 mg, 0.610 $\mathrm{mmol}$ ), Ni(COD) 2 (436 mg, $1.587 \mathrm{mmol}$ ), BPy (110 mg, 0.701 $\mathrm{mmol}$ ) and COD (172 mg, $1.587 \mathrm{mmol})$ in $7 \mathrm{~mL}$ of THF was reacted under microwave heating at $120{ }^{\circ} \mathrm{C}$ for $12 \mathrm{~min}$. The reaction mixture was quenched with water and extracted with chloroform. The collected organic phases were washed with aqueous $2 \mathrm{M} \mathrm{HCl}$, aqueous $\mathrm{NaHCO}_{3}$ solution, saturated, aqueous EDTA solution, and brine, and finally dried over $\mathrm{MgSO}_{4}$. Afterwards, the solvents were removed under vacuum. The resulting solid was dissolved in a small amount of 
chloroform and precipitated into $500 \mathrm{~mL}$ of methanol to afford the target polymer as a light-green solid. Subsequent Soxhlet extractions were carried out with methanol, acetone, ethyl acetate and chloroform, respectively. After re-precipitation of the chloroform-soluble fraction into methanol, the light-green polymer was obtained with $70 \%$ yield $(211 \mathrm{mg}) .{ }^{1} \mathrm{H}$ NMR (600 $\left.\mathrm{MHz}, \mathrm{C}_{2} \mathrm{D}_{2} \mathrm{Cl}_{4}, 60{ }^{\circ} \mathrm{C}\right) \delta 8.60-8.41(\mathrm{~m}, 2 \mathrm{H}), 7.86-7.62(\mathrm{~m}, 2 \mathrm{H})$, 7.48-6.87 (m, 21H). ${ }^{13} \mathrm{C}$ NMR (150 MHz, $\left.\mathrm{C}_{2} \mathrm{D}_{2} \mathrm{Cl}_{4}, 60{ }^{\circ} \mathrm{C}\right) 143.76$, 143.59, 143.43, 143.15, 142.26, 140.72, 140.51, 136.04, 134.62, $132.91,131.55,131.53,131.47,128.09,128.01,127.94,126.93$, $126.86,126.78,126.09,124.46,119.10,110.54 . M_{\mathrm{n}} 6800, M_{\mathrm{w}}$ 14300 , and $M_{\mathrm{w}} / M_{\mathrm{n}} 2.10$ (GPC, PS calibration).

Polymer PCzTPE0.5. A solution of compound 2 (300 mg, $0.457 \mathrm{mmol}$ ), compound 3 (200 mg, $0.457 \mathrm{mmol}$ ), Ni(COD) 2 (629 $\mathrm{mg}, 2.287 \mathrm{mmol})$, BPy (357 mg, $2.287 \mathrm{mmol}$ ) and COD (247 mg, $2.287 \mathrm{mmol}$ ) in $7 \mathrm{~mL}$ of $\mathrm{THF}$ was reacted under microwave heating at $120^{\circ} \mathrm{C}$ for $12 \mathrm{~min}$. The workup procedure was similar to that described for the preparation of PCzTPE. The light-green polymer was obtained with $54 \%$ yield (192 mg). ${ }^{1} \mathrm{H}$ NMR (600 $\left.\mathrm{MHz}, \mathrm{C}_{2} \mathrm{D}_{2} \mathrm{Cl}_{4}, 60{ }^{\circ} \mathrm{C}\right) \delta 8.49(\mathrm{~s}, 4 \mathrm{H}), 8.01-7.66(\mathrm{~m}, 4 \mathrm{H}), 7.58-6.94$ $(\mathrm{m}, 23 \mathrm{H}), 4.26(\mathrm{~s}, 2 \mathrm{H}), 1.88(\mathrm{~s}, 2 \mathrm{H}), 1.29(\mathrm{dd}, J=78.1,27.6 \mathrm{~Hz}$, $10 \mathrm{H}), 0.92-0.73(\mathrm{~m}, 3 \mathrm{H}) . M_{\mathrm{n}} 9200, M_{\mathrm{w}} 23400$, and $M_{\mathrm{w}} / M_{\mathrm{n}} 2.54$ (GPC, PS calibration).

\section{Results and discussion}

\section{Synthesis and characterization}

The synthesis routes to the monomers and polymers are depicted in Scheme 1. Monofluoro-TPE 1 was obtained by treating 4-fluorobenzophenone with diphenylmethyl lithium followed by acid-catalyzed dehydration. ${ }^{46}$ The $N$-carbazolyl-TPE derivative 2 was synthesized by catalyst-free $N$-arylation in a direct nucleophilic substitution of $\mathbf{1}$ as nonactivated
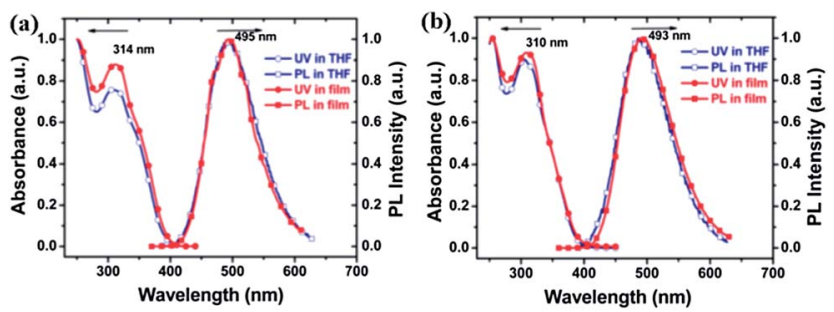

Fig. 1 Absorption and PL spectra (excitation wavelength: $320 \mathrm{~nm}$ ) of (a) PCZTPE and (b) PCZTPE0.5 in dilute THF solution $\left(10^{-5} \mathrm{M}\right)$ and as spin-coated films recorded at room temperature.<smiles>O=C(c1ccccc1)c1ccc(F)cc1</smiles>
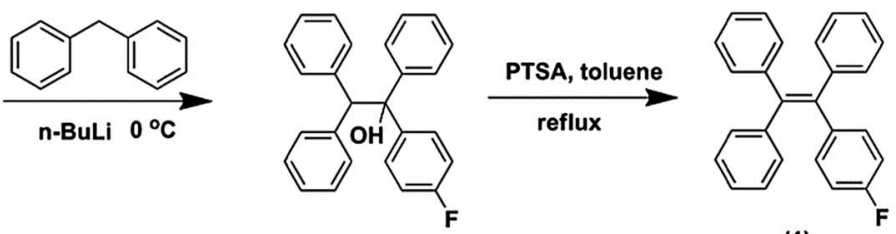

(1)

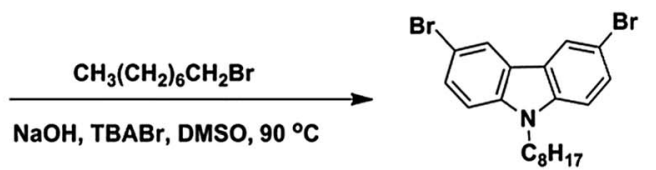

(3)

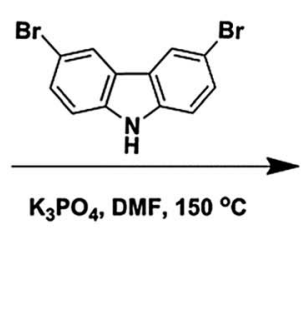<smiles>Brc1ccc2c(c1)c1cc(Br)ccc1n2-c1ccc(C(=C(c2ccccc2)c2ccccc2)c2ccccc2)cc1</smiles>

(2)
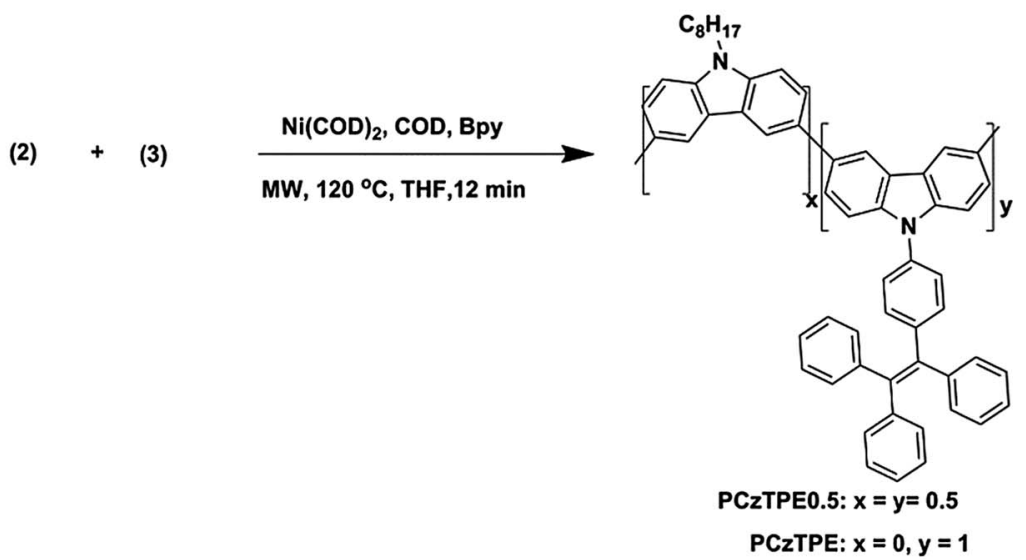

Scheme 1 Synthetic procedures for monomer and polymer synthesis. 

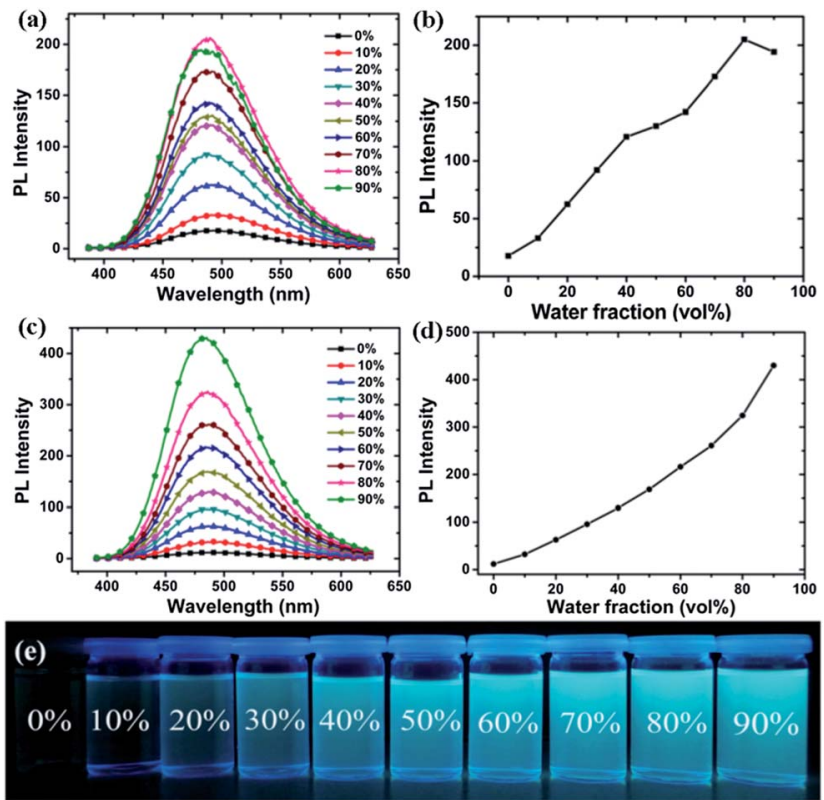

Fig. 2 PL spectra of (a) PCzTPE and (c) PCzTPE0.5 in THF-water mixtures with different water contents; increase of $\mathrm{PL}$ intensity with increasing water fraction for (b) PCzTPE and (d) PCzTPE0.5, respectively (polymer concentration: $10^{-5} \mathrm{M}$; excitation wavelength: 320 $\mathrm{nm}$ ); (e) fluorescence images of PCzTPE0.5 in THF-water mixtures with different water contents.

fluorobenzene with 3,6-dibromocarbazole. ${ }^{47}$ 3,6-Dibromo-9octylcarbazole $\mathbf{3}$ was synthesized according to a reported procedure. ${ }^{48}$ All monomers were fully characterized prior to polymerization. Homopolymer PCzTPE and random copolymer PCzTPE0.5 were synthesized from monomers 2 and 3 by Yamamoto-type coupling using $\mathrm{Ni}(\mathrm{COD})_{2}$ as a coupling reagent in a mixture of THF, COD and Bpy under microwave (MW) heating. ${ }^{49}$ Following these protocols we could obtain the target conjugated polymers in short reaction times. The chemical structures of the obtained polymers were confirmed by NMR spectroscopy, GPC, thermal analysis and optical spectroscopy.

\section{Thermal properties}

The thermal properties of PCzTPE0.5 and PCzTPE were investigated by TGA and DSC. Both polymers exhibit high thermal stability with $5 \%$ weight loss occurring at 490 and $430{ }^{\circ} \mathrm{C}$, respectively. In DSC analysis we could not record glass transitions $\left(T_{\mathrm{g}}\right)$ up to $300{ }^{\circ} \mathrm{C}$. High thermal stability is important for practical application in solid state sensors.

\section{Photophysical properties}

Fig. 1 shows the absorption and PL spectra of PCzTPE and PCzTPE0.5 in THF solution and solid state films. The absorption spectra of PCzTPE and PCzTPE0.5 are very similar, with solid state peak maxima at 314 and $310 \mathrm{~nm}$, respectively. In the PL spectra both polymers exhibit green fluorescence peaking around $495 \mathrm{~nm}$, both in solution and as thin films. This behavior is attributed to the incorporation of the TPE units they effectively suppress $\pi$-stacking in the condensed phase due
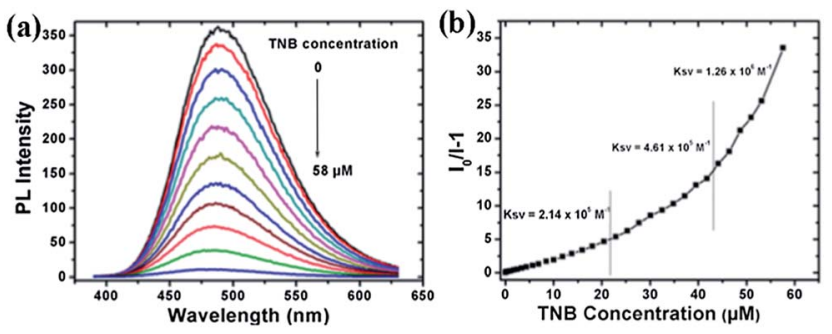

Fig. 3 (a) PL spectra of PCzTPE0.5 in THF-water $1: 9$ containing different amounts of TNB. Polymer concentration: $10^{-5} M_{;} \lambda_{\text {ex }}: 320$ $\mathrm{nm}$. (b) Stern-Volmer plots of PL intensity of PCzTPE0.5 $I_{0} / l-1$ versus TNB concentration $\left(I=\mathrm{PL}\right.$ intensity, $l_{0}=\mathrm{PL}$ intensity at a TNB concentration of $\mathrm{OM}$ ).

to the presence of the propeller-shaped TPE side chain. The photoluminescence quantum yields (PLQYs) of PCzTPE and PCzTPE0.5 in diluted THF solution, estimated by using quinine sulfate as the standard, have been determined as $1.1 \%$ and $0.8 \%$, respectively. The PLQYs distinctly increase to $20 \%$ and $21 \%$, respectively, in solid state films, 18- and 26-fold higher when compared to THF solutions. Evidently, the transition into the condensed state dramatically enhances the PL of the polymers. The AIE properties will be discussed in detail in the following paragraph.

To further investigate the AIE effect with the polymers PCzTPE and PCzTPE0.5, a series of PL spectra in THF-water mixtures with increasing water fraction were recorded. Fig. 2a and $c$ show PL spectra of the polymers in such water-THF mixtures. The PL intensity increases progressively with increasing water fraction for both polymers. Hereby, polymer PCzTPE0.5 showed a more pronounced AIE effect when compared to the PCzTPE copolymer. For PCzTPE the PL intensity is 11 times higher for a water content of $80 \%$ when compared to pure THF (Fig. 2b), and for PCzTPE0.5 35 times higher for a water content of $90 \%$ (Fig. 2d). As water is a nonsolvent for PCzTPE and PCzTPE0.5, both polymers are assumed to form solid-state aggregates in the THF-water mixtures with a high water content, thus exhibiting aggregation-induced PL enhancement: they are AIE active. Caused by the high rotational freedom of the TPE side-chain moieties in solution, a high internal conversion rate results in weak emission. Within the aggregated (solid) state, however, the rotation of phenyl rings of
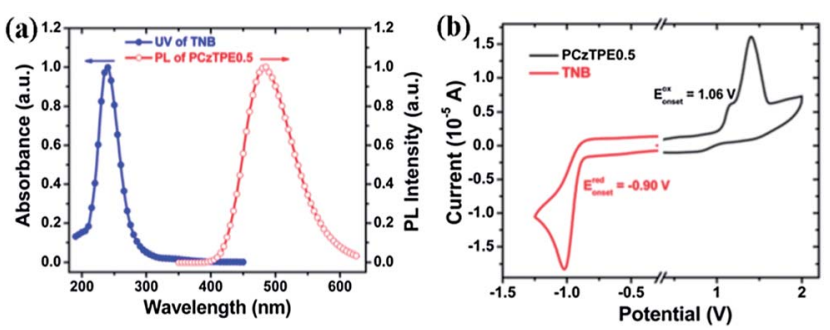

Fig. 4 (a) Normalized absorption spectrum of TNB and the PL spectrum of PCzTPE0.5 nanoaggregates in THF-water 1 : 9. (b) CV plots of PCzTPE0.5 in dichloromethane (oxidative scan) and TNB in acetonitrile (reductive scan), for the experimental conditions please see the Characterization of materials chapter. 
A
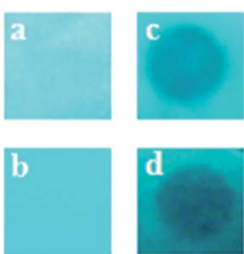

B
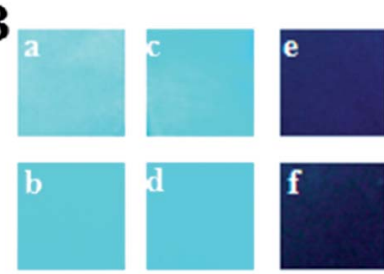

Fig. 5 Paper strip tests. (A) Vapor-mode detection of TNB: test strips before ( $a$ and $b$ ) and after ( $c$ and d) placing the strips on top of a glass vial containing solid TNB for 5 min; for PCzTPE (a and c) or PCzTPE0.5 (b and d), respectively. (B) Solution-mode detection of TNB: test strips before ( $a$ and $b$ ) and after dipping the strips into pure THF ( $c$ and $d)$ and into a $10^{-4} \mathrm{M}$ TNB solution in THF (e and f); for PCzTPE (a, c and e) or PCzTPEO.5 (b, $d$ and f), respectively.

the TPE units is strongly restricted, thus blocking non-radiative deactivation channels and leading to the AIE effect. Poly $(N-$ octyl-3,6-carbazole) without TPE side groups that was generated as a reference did not show any AIE activity.

\section{Explosive detection}

PCzTPE and PCzTPE0.5 should show good electron-donor ability due to their electron-rich polycarbazole backbones. Moreover, their twisted 3D-structure should create effective pathways for interchain exciton diffusion leading to amplified PL quenching properties. Based on the above presented results we started our investigations with aggregated PCzTPE0.5 in THF-water $1: 9$ (polymer concentration $10 \mu \mathrm{M}$ ). 1,3,5-Trinitrobenzene (TNB) was chosen as a prototypical nitroaromatic analyte. As shown in Fig. 3a, the PL intensity of PCzTPE0.5 in THF-water $1: 9$ decreases progressively during addition of TNB, without changing the PL peak position, suggesting that different emissive species are not formed. The onset of PL quenching is found for addition of $50 \mathrm{nM} \mathrm{TNB}$, low enough for the detection of submillimolar TNB concentrations. For a TNB concentration of $58 \mu \mathrm{M}$, the PL of the dispersed polymer nanoaggregates is fully quenched. The quenching response was analyzed by fitting the data with the Stern-Volmer equation, as depicted in Fig. 3b. For TNB concentrations below $21 \mu \mathrm{M}$, the Stern-Volmer plot is linear with a quenching constant of $2.14 \times 10^{5} \mathrm{M}^{-1}$. For a higher analyte concentration, the curve bends upward, thus demonstrating an amplified quenching. ${ }^{50}$ The quenching constant reaches $c a .1 .26 \times 10^{6} \mathrm{M}^{-1}$ between TNB concentrations of $43 \mu \mathrm{M}$ and $58 \mu \mathrm{M}$. This amplified quenching is attributed to the twisted 3D topology of the polymer chains in the nanoaggregates, leading to the formation of an increased number of quenching sites that can interact with TNB molecules and/or to an improved exciton diffusion to quenching sites. ${ }^{51}$

Fig. 4a shows that there is no spectral overlap between the absorption spectrum of TNB and the PL spectrum of PCzTPE0.5 (as a prerequisite for Förster-type energy transfer) thus indicating that the main quenching mechanism for TNB addition should be an excited state charge transfer between the excited state of the host and the ground state of the TNB quencher. The occurrence of charge transfer was further confirmed by cyclic voltammetry (Fig. 4b). The HOMO (highest occupied molecular orbital) level of PCzTPE0.5 was estimated to be $c a$. $-5.1 \mathrm{eV}$, and the LUMO (lowest unoccupied molecular orbital) level of TNB to be $c a$. $-3.1 \mathrm{eV}$. Considering an optical bandgap $\left(E_{\mathrm{g}}\right)$ of $3.2 \mathrm{eV}$ for PCzTPE0.5 from the onset of its UV/vis absorption band, the LUMO level of PCzTPE0.5 is calculated to be $c a .-1.9 \mathrm{eV}$. Therefore, the LUMO energy $(-1.9 \mathrm{eV})$ of PCzTPE0.5 allows for an excited state electron transfer to the lower-lying LUMO level of TNB with a LUMO-LUMO offset of $c a .1 .2 \mathrm{eV} . .^{52}$

For practical explosive detection, the availability of solid state sensor devices is of primary importance. Towards this goal, we prepared test strips by dip-coating Whatman filter paper into solutions of PCzTPE and PCzTPE0.5 in THF $\left(10^{-4} \mathrm{M}\right)$ followed by drying the strips in an air stream. First, for vapormode tests, we placed the fluorescent paper strips on top of a glass vial containing solid TNB for $5 \mathrm{~min}$ at room temperature. In this way, a circular area of the strip was exposed to TNB vapor. Within the exposed area the PL of the polymers was obviously distinctly quenched (Fig. 5A). Second, for solution tests, the test strips containing both polymers were dipped into pure THF (as reference) and a solution of TNB in THF $\left(10^{-4} \mathrm{M}\right)$. As shown in Fig. 5B, the fluorescence of the strips was quenched completely after contact with the TNB solution for both polymers. The reference strips dipped into pure THF did not show significant PL quenching thus demonstrating that the majority of the polymers remain adsorbed at the test strips. These first promising results demonstrate the potential of our new polycarbazole-type polymers PCzTPE0.5 and PCzTPE for the fabrication of solid state sensors for nitroaromatic explosives with sufficient sensitivity.

\section{Conclusions}

In summary, two poly(3,6-carbazole)s with AIE-active tetraphenylethylene (TPE) side chains have been successfully synthesized. The polymers combine the electron-deficient character of the polycarbazole backbone and the AIE behavior of the TPE containing side chains. So, both polymers PCzTPE and PCzTPE0.5 show distinct AIE properties. For sensing of nitroaromatic explosives PL quenching experiments were carried out. Aggregated PCzTPE0.5 shows amplified PL quenching during trinitrobenzene (TNB) addition in THF-water mixtures $(1: 9, \mathrm{v} / \mathrm{v})$ with a maximum Stern-Volmer quenching constant of $1.26 \times 10^{6} \mathrm{M}^{-1}$. Solid-state paper strips with deposits of both polymers show TNB-induced PL quenching, both towards TNB vapor or TNB solution thus demonstrating promising practical application potential in solid state sensors for nitroaromatic explosives. Other possible applications (e.g. in OLEDs) are currently tested.

\section{Acknowledgements}

W.D. would like to thank for financial support from the fellowship program of the China Scholarship Council. A.P.C. would like to thank the DAAD for a PhD fellowship. Thanks to Anke Helfer for performing the GPC, TGA and DSC analyses and to João Pina for the measurement of solid state photoluminescence quantum yields. 


\section{Notes and references}

1 M. Belletete, J. Bouchard, M. Leclerc and G. Durocher, Macromolecules, 2005, 38, 880.

2 R. Jakubiak, C. J. Collison, W. C. Wan and L. Rothberg, J. Phys. Chem. A, 1999, 103, 2394.

3 M. Grell, D. D. C. Bradley, X. Long, T. Chamberlain, M. Inbasekaran, E. P. Woo and M. Soliman, Acta Polym., 1998, 49, 439.

4 J. Wang, Y. Zhao, C. Dou, H. Sun, P. Xu, K. Ye, J. Zhang, S. Jiang, F. Li and Y. Wang, J. Phys. Chem. B, 2007, 111, 5082.

5 S.-F. Lim, R. H. Friend, I. D. Rees, J. Li, Y. Ma, K. Robinson, A. B. Holmes, E. Hennebicq, D. Beljonne and F. Cacialli, Adv. Funct. Mater., 2005, 15, 981.

6 C.-W. Wu, C.-M. Tsai and H.-C. Lin, Macromolecules, 2006, 39, 4298.

7 A. Kraft, A. C. Grimsdale and A. B. Holmes, Angew. Chem., Int. Ed., 1998, 37, 402.

8 S. Setayesh, A. C. Grimsdale, T. Weil, V. Enkelmann, K. Müllen, F. Meghdadi, E. J. W. List and G. Leising, J. Am. Chem. Soc., 2001, 123, 946.

9 S. Hecht and J. M. J. Frechet, Angew. Chem., Int. Ed., 2001, 40, 74.

10 L. Chen, S. Xu, D. McBranch and D. Whitten, J. Am. Chem. Soc., 2000, 122, 9302.

11 C. Fan, S. Wang, J. W. Hong, G. C. Bazan, K. W. Plaxco and A. J. Heeger, Proc. Natl. Acad. Sci. U. S. A., 2003, 100, 6297.

12 J. Luo, Z. Xie, J. W. Y. Lam, L. Cheng, H. Chen, C. Qiu, H. S. Kwok, X. Zhan, Y. Liu, D. Zhu and B. Z. Tang, Chem. Commun., 2001, 1740.

13 B. Z. Tang, X. Zhan, G. Yu, P. P. S. Lee, Y. Liu and D. Zhu, J. Mater. Chem., 2001, 11, 2974.

14 Z. Xie, B. Yang, W. Xie, L. Liu, F. Shen, H. Wang, X. Yang, Z. Wang, Y. Li, M. Hanif, G. Yang, L. Ye and Y. Ma, J. Phys. Chem. B, 2006, 110, 20993.

15 Y. Hong, J. W. Y. Lam and B. Z. Tang, Chem. Commun., 2009, 4332.

16 R. Hu, J. W. Y. Lam, Y. Liu, X. Zhang and B. Z. Tang, Chem.Eur. J., 2013, 19, 5617.

17 S. Yin, Q. Peng, Z. Shuai, W. Fang, Y. H. Wang and Y. Luo, Phys. Rev. B: Condens. Matter Mater. Phys., 2006, 73, 205409.

18 Q. Peng, Y. Yi, Z. Shuai and J. Shao, J. Am. Chem. Soc., 2007, 129, 9333.

19 X. Fan, J. Sun, F. Wang, Z. Chu, P. Wang, Y. Dong, R. Hu, B. Z. Tang and D. Zou, Chem. Commun., 2008, 2989.

20 J. W. Grate, Chem. Rev., 2008, 108, 726.

21 J.-S. Yang and T. M. Swager, J. Am. Chem. Soc., 1998, 120, 5321.

22 J.-S. Yang and T. M. Swager, J. Am. Chem. Soc., 1998, 120, 11864.

23 S. W. Zhang and T. M. Swager, J. Am. Chem. Soc., 2003, 125, 3420.

24 M. E. Walsh, Talanta, 2001, 54, 427.

25 Y. Jehuda, Mass Spectrom. Rev., 1982, 1, 257.

26 J. C. Mathurin, T. Faye, A. Brunot and J. C. Tabet, Anal. Chem., 2000, 72, 5055.
27 J. M. Sylvia, J. A. Janni, J. D. Klein and K. M. Spencer, Anal. Chem., 2000, 72, 5834.

28 E. Wallis, T. M. Griffin, N. Popkie Jr, M. A. Eagan, R. F. McAtee, D. Vrazel and J. McKinly, Proc. SPIE, 2005, 5795, 54.

29 G. A. Eicaman and J. A. Stone, Anal. Chem., 2004, 1, 390.

30 M. Krausa and K. Schorb, J. Electroanal. Chem., 1999, 461, 10.

31 H. Nie, Y. Zhao, M. Zhang, Y. Ma, M. Baumgarten and

K. Müllen, Chem. Commun., 2011, 47, 1234.

32 D. T. McQuade, A. E. Pullen and T. M. Swager, Chem. Rev., 2000, 100, 2537.

33 C. McDonagh, C. S. Burke and B. D. MacCraith, Chem. Rev., 2008, 108, 400.

34 X. Liu, Y. Xu and D. Jiang, J. Am. Chem. Soc., 2012, 134, 8738. 35 S. W. Thomas, G. D. Joly and T. M. Swager, Chem. Rev., 2007, 107, 1339.

36 Y. Salinas, R. Martinez-Manez, M. D. Marcos, F. Sancenon, A. M. Costero, M. Parra and S. Gil, Chem. Soc. Rev., 2012, 41, 1261.

37 S. W. Thomas, G. D. Joly and T. M. Swager, Chem. Rev., 2007, 107, 1339.

38 H. Li, H. Wu, E. Zhao, J. Li, J. Z. Sun, A. Qin and B. Z. Tang, Macromolecules, 2013, 46, 3907.

39 W. Wu, S. Ye, R. Tang, L. Huang, Q. Li, G. Yu, Y. Liu, J. Qin and Z. Li, Polymer, 2012, 53, 3163.

40 P. Lu, J. W. Y. Lam, J. Liu, C. K. W. Jim, W. Yuan, N. Xie, Y. Zhong, Q. Hu, K. S. Wong, K. K. L. Cheuk and B. Z. Tang, Macromol. Rapid Commun., 2010, 31, 834.

41 W. Wu, S. Ye, L. Huang, L. Xiao, Y. Fu, Q. Huang, G. Yu, Y. Liu, J. Qin, Q. Li and Z. Li, J. Mater. Chem., 2012, 22, 6374.

42 W. Wu, S. Ye, G. Yu, Y. Liu, J. Qin and Z. Li, Macromol. Rapid Commun., 2012, 33, 164.

43 S. Grigalevicius, L. Ma, G. Qian, Z. Xie, M. Forster and U. Scherf, Macromol. Chem. Phys., 2007, 208, 349.

44 S. A. Patil, U. Scherf and A. Kadashchuk, Adv. Funct. Mater., 2003, 13, 609.

45 B. Souharce, C. J. Kudla, M. Forster, J. Steiger, R. Anselmann, H. Thiem and U. Scherf, Macromol. Rapid Commun., 2009, 30, 1258.

46 M. Banerjee, S. J. Emond, S. V. Lindeman and R. Rathore, J. Org. Chem., 2007, 72, 8054.

47 F. Diness and D. P. Fairlie, Angew. Chem., Int. Ed., 2012, 51, 8012.

48 D. Hu, G. Cheng, P. Lu, H. Liu, F. Shen, F. Li, Y. Lv, W. Dong and Y. Ma, Macromol. Rapid Commun., 2011, 32, 1467.

49 F. Galbrecht, T. W. Bünnagel, U. Scherf and T. Farrell, Macromol. Rapid Commun., 2007, 28, 387.

50 C. Y. K. Chan, Z. Zhao, J. W. Y. Lam, J. Liu, S. Chen, P. Lu, F. Mahtab, X. Chen, H. H. Y. Sung, H. S. Kwok, Y. Ma, I. D. Williams, K. S. Wong and B. Z. Tang, Adv. Funct. Mater., 2012, 22, 378.

51 J. Li, J. Liu, J. W. Y. Lam and B. Z. Tang, RSC Adv., 2013, 3, 8193.

52 J. Wang, J. Mei, W. Yuan, P. Lu, A. Qin, J. Sun, Y. Ma and B. Z. Tang, J. Mater. Chem., 2011, 21, 4056. 